\title{
RUBELLA SEROPREVALENCE IN CHILDREN IN DOGANKENT, A RURAL AREA OF ADANA PROVINCE IN TURKEY, JANUARY- FEBRUARY 2005
}

\author{
N Aytac (natac@cu.edu.tr) ${ }^{1}$, A B Yucel ${ }^{1}$, H Yapicioglu², F Kibar ${ }^{3}, 0$ Karaomerlioglu ${ }^{1}$, M Akbaba $^{1}$ \\ 1. Department of Public Health, Faculty of Medicine, Çukurova University, Adana, Turkey \\ 2. Department of Paediatrics, Faculty of Medicine, Çukurova University, Adana, Turkey \\ 3. Central Laboratory, Faculty of Medicine, Çukurova University, Adana, Turkey
}

This article was published on 17 December 2009.

Citation style for this article: Aytac N, Yucel AB, Yapicioglu H, Kibar F, Karaomerlioglu 0, Akbaba M. Rubella seroprevalence in children in Dogankent, a rural area of Adana province in Turkey, January-February 2005. Euro Surveill. 2009;14(50):pii=19444. Available online: http://www.eurosurveillance.org/ViewArticle.aspx?ArticleId=19444

\begin{abstract}
A cross-sectional study was performed to determine the rubella seroprevalence in 331 children aged between 0 and 59 months in Turkey who were not vaccinated for rubella and lived in the area covered by Dogankent Health Center, a rural area with a large proportion of residents of low socioeconomic status. Rubella seropositivity was found to be low, with $17.5 \%$, increased with age and low socioeconomic level, and was particularly high in children who live in a household with one member going to school, and in children of uneducated parents $(p<0.05)$. The asymptomatic infection rate was $98.3 \%$. There was no significant difference in seropositivity with regards to the gender, history of rubella infection, size of the household, or number of children at home ( $p>0.05)$. Rubella vaccine has only been included into the national vaccination programme in the form of the measles-mumps-rubella (MMR) vaccine since 2006 and is performed at the age of 12 months, in the first year of primary school and at the age of about 15 years. In order to eliminate rubella and congenital rubella syndrome, it is necessary that use of MMR vaccine is expanded to include the children born before 2006 .
\end{abstract}

\section{Introduction}

Although rubella is a self-limiting disease in childhood, it can cause congenital rubella syndrome (CRS) when the mother is infected during the first trimester of pregnancy. In CRS, fetus and placenta are infected following maternal viraemia, which can result in abortion, premature birth or cataract, retinopathy, deafness, cardiac defects, hepatitis, haemolytic anaemia, thrombocytopenia, endocrinopathies, microcephaly, psychomotor retardation and progressive rubella encephalitis. The risk of clinical manifestations in the fetus or newborn decreases with the gestational age at the time of vertical transmission [1-3]. The most effective way to eliminate CRS is vaccination against rubella. A rubella elimination strategy should be based on universal childhood vaccination as well as immunisation of susceptible women at childbearing age. Unfortunately, there is no information about the CRS rate in Turkey.

In Turkey, rubella vaccine has been on the market since 1989 and has been administered in the form of the combined measlesmumps-rubella (MMR) vaccine, mainly in private practices and paid by the parents. A study conducted in Istanbul in 2002 reported that $13.3 \%$ of children were vaccinated by MMR [4]. Rubella vaccine has been incorporated into the Turkish national immunisation programme only in 2006. In the beginning of vaccination programme, it was applied as MMR vaccine at the ages of 12 months and ca. seven years (in the first year of primary school), and as rubella vaccine at the age of about 15 years.

In studies on rubella seropositivity carried out in children in Turkey, Aksit et al. reported a seropositivity of $38.3 \%$ in $1-4$ yearolds in Izmir in 1999 [5] and Cavusoglu et al. one of $12.5 \%$ in $2-5$ year-olds in Istanbul in 2001[6]. Ay et al. reported $66.7 \%$ rubella seropositivity in primary school students in a rural district in Istanbul in 2003 [7]. In 2006, Gurgoze et al. reported a seropositivity of $47.3 \%$ in $1-4$ year-olds and of $89.2 \%$ in $13-16$ year-olds in Elazig, a city in eastern Turkey [8]. In Adana, Karakoc et al. found the seropositivity to be $92.5 \%$ in adolescent girls in 1999 [9] and in 2006, Oner et al. found it to be $93.7 \%$ in the same age group in Edirne, a city in northwest Turkey [10]. In pregnant women and women of childbearing age, reports from Turkey indicate that rubella seropositivity varies widely, ranging from $55.0 \%$ in Mersin province to $100 \%$ in Istanbul city $[11,12]$. Therefore, many women may be susceptible to rubella infection especially in rural areas. In the beginning of the rubella vaccination policy, children aged 1-6 years may not be vaccinated until they go to primary school, and as most of them are seronegative for rubella, they may be a risk for pregnant women. Hence, the objective of this study was to determine rubella seroprevalence in 0-59 months-old unvaccinated children in Dogankent, a district in Adana, Turkey.

\section{Materials and Methods}

Adana is an industrialised city in the southern part of Turkey with a population of approximately two million. Between 11 January and 17 February 2005, a cross-sectional study was conducted in Dogankent, a rural district, $20 \mathrm{~km}$ from of Adana, with a low socio-economic level and a population of 12,000. Dogankent has three elementary schools and one health centre. Main employment is in agriculture and stockbreeding. Although the mean size of a household in Turkey is four members, the mean household in Dogankent had seven members. Most of the adults were unemployed [13].

A systematic sampling method stratified by age and sex was applied, on the basis of data from the Dogankent primary health centre. This primary health centre was established in 1982 and 
is under the supervision of the Department of Public Health of Cukurova University for which it serves as research and training area. The lowest seropositivity in 0-59 month-old children reported in all areas in Turkey was $12.5 \%$ [6]. At the time of study, 1,233 children between 0 and 59 months of age were living in Dogankent. The sample size of the study was calculated as 330 based on the $12.0 \%$ estimate of rubella immunity, with a $95 \%$ confidence level and worst acceptable result as $9 \%$. The list of the subjects was obtained from the directorate of the Dogankent health centre. An additional 33 reserve subjects were also defined from the same age group, to be called if any of the 330 children could not be reached.

This sample size of 331 subjects comprised $26.8 \%$ of the $0-59$ month-old children in the district. A maximum of one child from every house was included to the study. If we could not reach a child, a subject was chosen from 33 children on a reserve list. Subjects who had a telephone number were called to the primary health centre; those who did not were visited at home by one of the investigators. Twenty-nine subjects could not be included in the study for the following reasons: three did not want to participate, 26 moved away. Instead, 29 children from the reserve list were included in the study.

A questionnaire was completed about socio-demographic features, rubella vaccination and history of rubella infection of each child and family. Parents were asked if their child had ever been diagnosed for rubella by a physician or vaccinated with rubella vaccine, about the number people living in the household and the

\section{T A B L E 1}

Children, by age and sex, participating in the rubella seroprevalence study in Dogankent Turkey, JanuaryFebruary $2005(n=331)$

\begin{tabular}{|l|c|c|c|c|}
\hline \multirow{2}{*}{ Age group (months) } & \multicolumn{2}{|c|}{ Boys } & \multicolumn{2}{c|}{ Girls } \\
\hline $0-11$ & $n$ & 50.0 & 24 & 50.0 \\
\hline $12-23$ & 24 & 51.4 & 36 & 48.6 \\
\hline $24-35$ & 38 & 44.0 & 42 & 56.0 \\
\hline $36-47$ & 33 & 53.6 & 32 & 46.4 \\
\hline $48-59$ & 37 & 46.2 & 35 & 53.8 \\
\hline Total & 30 & 48.9 & 169 & 51.1 \\
\hline
\end{tabular}

F I G U R E

Age-specific rubella seropositivity in children of low socioeconomic status in Dogankent Turkey, January-February 2005 (n=331)

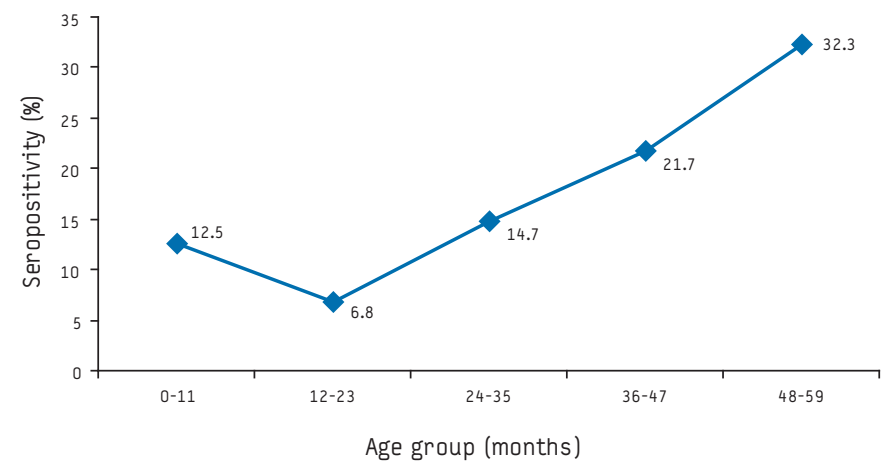

number of siblings aged 0-14 years living at home, the number of siblings going to school, and about the parents' employment and education level. Educational level of the parents was classified either as no education (not even primary school) or as having attended primary school (not necessarily graduating). Employement was defined according to the International Labour Organization [14]. There were four types of health insurance schemes in Turkey at the time of study: one for civil servants, one for self-employed people, one for workers, and a green card which covers the very poor people. People not included in any of these four insurance systems had to pay for healthcare. Since 2008 children under the age of 18 years have been entitled to free healthcare.

With permission of the parents, $3-5 \mathrm{ml}$ venous blood was obtained from each child. Serum samples were stored at -20 o C and tested for rubella antibodies. Anti-rubella IgG was analysed by ELISA (DSL-05-10-RBG; Diagnostic System Laboratories). Values over 0.283 were defined as positive for the presence of antibody. The statistical analysis was done using SPSS-10.0, and chi-square test. A p value of $<0.05$ was accepted as statistically significant.

The study was approved by the local ethics committee of the faculty of medicine and informed consent was obtained from all parents.

\section{Results}

The study was carried out in 331 children (162 boys, 169 girls). The mean age of the children was $30.3 \pm 16.0$ months (range: 1-59 months, median age: 29 months). There was no statistically significant difference in the number of children in terms of sex and age group ( $p>0.05)$. The age distribution of the children is shown in Table 1.

Of the 331 children, 135 (40.8\%) had no social health insurance, 141 (42.6\%) had the green card, and 55 (16.6\%) belonged to a social insurance system. Half of the fathers (48.9\%) and almost all (99.1\%) of the mothers were unemployed; $23.9 \%$ of fathers were workers, and $25.1 \%$ were self-employed.

None of the children participating in the study had received the rubella vaccine. Fifty-eight children (17.5\%) were positive for rubella antibodies. The Figure shows the rubella seropositivity in different age groups. Rubella seropositivity increased with age $(p<0.05)$. There was no significant difference between boys and girls in terms of rubella seropositivity $(p>0.05)$.

Only five children were reported by the parents to have a history of rubella infection and one of those five had rubella antibodies. However, 57 (17.5\%) of the 326 children without reported rubella history were positive for rubella antibody. Thus 57 of 58 children had negative rubella history, although they had had the infection in the past. Rubella seropositivity was not different between children who had a family member with $(20.0 \%)$ or without $(17.5 \%)$ rubella history $(p>0.05)$. Neither was there any statistically significant relation between household size and the number of children in the house ( $p>0.05)$. The rubella seropositivity was higher in children living in a household with members who were going to school (Table $2, p<0.05)$. The parent's educational level was inversely associated with the prevalence of anti-rubella antibodies in the sense that as the educational level increased rubella seropositivity decreased (Table 2, p<0.05). 


\section{Discussion}

In our study, rubella seropositivity was $17.5 \%$ among children aged 0-59 months. The major limitation of our study is that the results are from a single centre. Therefore our results may not necessarily be representative for other parts of Turkey. However, they could provide a benchmark for future assessments. In other studies carried out in Turkey, rubella seropositivity ranged from $22.5 \%$ [15] to $38.3 \%$ [5] in $0-1$ year-olds, $47.3 \%$ [8] to $51.3 \%$ [16] in $1-4$ year-olds, $12.5 \%$ in $2-5$ year-olds [6] and $73.1 \%$ in $2-6$ year-olds [15]. In adolescents, seropositivities of $92.5 \%$ [9] and 93.7\% [10] have been reported. In developing countries, rubella seropositivity was found to be $97.0 \%$ in 2-7 year-olds in Iran [17], $69.2 \%$ in $1-5$ year-olds in India [18] and $58.0 \%$ in $2-4$ year-olds in Zaire [19]. The rubella seropositivity we found in our study was higher than the $12.5 \%$ observed by Çavusoglu et al. [6], but lower than those found in the other studies in similar age groups. This low level of rubella seropositivity we observed in Dogankent may be due to the geographic region or the fact that the study was performed in a rural area.

In the present study, rubella seropositivity was highest in the age group of 48-59 month-olds. Although rubella can be encountered at all ages, it is generally seen in the age group of 5-9 year-olds in countries that do not have routine rubella vaccination and rarely in those under one year of age due to maternal antibodies [1]. Several studies report that maternal antibodies are eliminated rapidly in the first 5-8 months of life [20-22]. The drop in seropositivity from $12.5 \%$ in the age group $0-11$ months to $6.6 \%$ in the age group $12-23$ months that we observed is probably due to the elimination of maternal antibodies.

Serologic studies conducted in Jordan [23], Nigeria [24], Yemen [25], Saudi Arabia [26], Lebanon [27], Taiwan [28], Italy [29], Ethiopia [30] in the past 20 years show that seropositivity increases with age. Seroprevalence data from the European SeroEpidemiology Network (ESEN) study performed between 1996 and 2003 showed that women in several countries were not sufficiently protected against rubella infection. According to the European
Centre for Disease Prevention and Control (ECDC), 1,498 rubella cases were reported from 22 European countries in 2005, with the highest incidences in Lithuania (3.44 per 100,000) and the Netherlands (2.23 per 100,000 ) [31]. Rubella susceptibility studies in our country also showed that seropositivity increases by age [6-11, 32]. Similarly, our study revealed that seropositivity increased from the 12th month of age, and this is in line with the findings in the literature.

Of 331 children in our study, only five had a history of rubella (as reported by the parents) and only in one of them, rubella seropositivity was determined. However, rubella seropositivity was found in $57(17.5 \%)$ of the 326 children for whom no rubella history was reported. Thus, $98.3 \%$ of the children with rubella antibodies must have experienced an asymptomatic infection. However, the parents may have been unaware of infection symptoms or there may be recall problems. In a study by Kanbur et al. in adolescents [33], $66.0 \%$ of the seropositive cases had a positive history; however, the children in that study had been asked if they had had an eruptive disease, not specifically rubella. Two possible explanations for the lower rate of rubella history in seropositive children in our study, in comparison to Kanbur et al. [33] could be that the children in our study were younger and that we asked whether they had a history of rubella rather than any eruptive disease. The fact that the majority of cases were asymptomatic emphasises the importance of serological studies in determining the definite prevalence of rubella in a community.

In our study, the rubella seroprevalence in children with parents who had education of any level was statistically lower than that in children with parents who never had any education. We have no explanation why this would be the case for an air-borne infection such as rubella. A higher number of infectious diseases in children of parents (especially mothers) with low education and low socioeconomic status is to be expected, as also observed by other authors [8,34]. However, Karakoc et al. [9] did not find a relation between rubella seropositivity and socioeconomic status.

\section{TA B L E 2}

Rubella seropositivity in children according to parents' education, siblings going to school, sex and number of people living at home in children of low socioeconomic status in Dogankent Turkey, January-February $2005(n=331)$

\begin{tabular}{|c|c|c|c|c|c|c|c|c|}
\hline & & \multicolumn{2}{|c|}{ Seropositivity } & \multicolumn{2}{|c|}{ Seronegativity } & \multicolumn{2}{|c|}{ All } & \multirow{2}{*}{ p value } \\
\hline & & $n$ & $\%^{\mathrm{a}}$ & $n$ & $\%^{a}$ & $\mathrm{n}$ & $\%^{b}$ & \\
\hline \multirow{2}{*}{ Gender } & Boys & 26 & 16.0 & 136 & 84.0 & 162 & 48.9 & \multirow{2}{*}{0.49} \\
\hline & Girls & 32 & 18.9 & 137 & 81.1 & 169 & 51.1 & \\
\hline \multirow{2}{*}{ Mother's educational status } & Not educated & 39 & 22.4 & 135 & 77.6 & 174 & 52.6 & \multirow{2}{*}{0.02} \\
\hline & Primary school or high school & 19 & 12.1 & 138 & 87.9 & 157 & 47.4 & \\
\hline \multirow{2}{*}{ Father's educational status } & Not educated & 18 & 26.5 & 50 & 73.5 & 68 & 20.5 & \multirow[t]{2}{*}{0.045} \\
\hline & Primary school or high school & 40 & 15.2 & 223 & 84.8 & 263 & 79.5 & \\
\hline \multirow{2}{*}{ Siblings going to school } & No & 20 & 12.3 & 142 & 87.7 & 162 & 48.9 & \multirow{2}{*}{0.02} \\
\hline & Yes & 38 & 22.5 & 131 & 77.5 & 169 & 51.1 & \\
\hline \multirow{3}{*}{ Number of people living at home } & $3-4$ & 10 & 12.5 & 70 & 87.5 & 80 & 24.2 & \multirow{3}{*}{0.11} \\
\hline & $5-6$ & 22 & 17.2 & 106 & 82.8 & 128 & 38.7 & \\
\hline & $7+$ & 26 & 21.1 & 97 & 78.9 & 123 & 37.1 & \\
\hline \multicolumn{2}{|c|}{ Total } & 58 & 17.5 & 273 & 82.5 & 331 & 100 & \\
\hline
\end{tabular}

a Percentage refers to the total in the same row.

b Percentage refers to the sum of totals in the column. 
Whether or not the children had a family member with a history of rubella infection did not make a statistical difference in terms of rubella seropositivity. One reason for this may be the fact that rubella infection is not as contagious as measles and chickenpox. While one measles case can infect 10-14 other people, a rubella case can spread to five or six people [2], and rubella inter-household infection is $50-60 \%$ [3]. Also, as $25-60 \%$ of rubella infections are asymptomatic [2,3], it is not possible to know whether people reporting no history of rubella are actually seronegative or not, which would result in an underestimation of cases in households with a history of rubella. Another reason may be the fact that poor people from low socioeconomic background might not have a chance to see a doctor. This finding of our study can therefore not be considered to be reliable.

Although crowding is known to play a role in the dissemination of rubella, we did not observe a statistically significant difference between rubella seropositivity and the number of household members. However, the risk of rubella was 1.6 times higher in children living in a household of seven or more members than in children living in a household of three or four people (21.1\% versus $12.5 \%$ seropositivity).

In our study, the number of siblings did not increase the seropositivity, but seropositivity was higher if the child had a sibling going to school (22.5\% versus $12.3 \%$ ). It is well known that rubella is less frequent in children before they have started school. Cengiz et al. [16] reported that rubella seropositivity was $12.5 \%$ before school and increased to $65.3 \%$ in primary school. Moreover, our study did not detect a statistically significant difference between rubella seropositivity and the presence in the household of children aged between 0-6 years. Rubella is seen mostly in five to nine year-old children and the rubella incidence reaches its peak in this age group [3]. The infection rate of the disease is about $100 \%$ in susceptible people in closed quarters such as schools and military barracks and 50 60\% in the home environment [3]. Higher rubella seropositivity in children with brothers or sisters in school is therefore an expected finding,

\section{Conclusion}

Rubella vaccination was integrated into the national immunisation programme in Turkey in the form of MMR vaccination only in 2006. In our study, rubella seropositivity was low in children aged between 0-59 months. For this reason, it is necessary to ensure that MMR vaccination is expanded nationwide to cover the children born before 2006. Epidemiological studies should continue as the epidemiological characteristics of the disease may change depending on the uptake of MMR vaccination, while seroprevalence studies should continue in order to determine the seroconversion rate and period of preventive effectiveness of $M M R$ vaccination. In order to eradicate rubella and CRS, it is necessary to vaccinate women at child-bearing age who are found to be susceptible as a result of serological tests and children born before 2006 with rubella vaccination.

\section{Acknowledgements}

This study was financed by Cukurova University Scientific Research Fund, under project number TF2004LTP3, as a thesis for a specialised medical degree. The laboratory work for the study was performed in the Central Laboratory of the Balcali Hospital of Çukurova University. We take this chance to thank the staff of Adana Provincial Directorate of Health and Dogankent Health Centre for their contribution to this study.

\section{References}

1. Gershon AA. Rubella Virus (German Measles). Principles and Practice of Infectious Diseases Volume 2. 5th ed. Mandell GL, Bennett JE, Dolin R, editors. Oxford: Churchill Livingstone; 2000: p. 1708-14.

2. Maldonado Y. Rubella. Nelson Textbook of Pediatrics. 16th ed. In: Behrman RE, Kliegman RM, Jenson HB, editors. Philadelphia: WB Saunders Company; 2000: p. 951-4.

3. Krugman S, Katz SL, Gershon AA, Wilfert CM. Infectious Diseases of Children. 9th ed. St. Louis: Mosby Year Book; 1992: p. 381-401.

4. Topuzoglu A, Ozaydin GA, Cali S, Cebeci D, Kalaca S, Harmanci H. Assessment of sociodemographic factors and socio-economic status affecting the coverage of compulsory and private immunization services in Istanbul, Turkey. Public Health. 2005;119(10):862-9.

5. Aksit S, Egemen A, Ozacar T, Kurugol Z, Keskinoglu P, Tasbakan M, et al. Rubella seroprevalence in an unvaccinated population in İzmir: recommendations for rubella vaccination in Turkey. Pediatr Infect Dis J. 1999;18(7):577-80.

6. Cavusoglu S, Oncul O, Erdemoglu A, Ozsoy MF, Emekdas G. Çocuk ve eriskin serum orneklerinde rubella seroprevalansi [Rubella seroprevalence in ser of children and adults]. [Turkish]. Infeksiyon Dergisi [Turkish J Infect]. 2001;15:419-424.

7. Ay P, Topuzoğlu A, Korukluoglu G, Cali S. Rubella seroprevalence among first-grade primary school students in a district in Istanbul. Public Health 2006;120(3):267-73.

8. Gurgoze MK, Yךlmaz E, Godekmerdan A, Akca Z, Dogan Y, Akarsu S, et al. Seroprevalence of mumps, varicella and rubella antibodies in children 1-16 years of age in eastern Turkey. Turk J Pediatr. 2006;48(3):185-8.

9. Karakoc GB, Altıntas DU, Kılıc B, Karabay A, Mungan NO, Y 7 lmaz M, et al. Seroprevalence of rubella in school girls and pregnant women. Eur $J$ Epidemiol. 2003;18(1): 81-4.

10. Öner N, Vatansever U, Karasalihoglu S, Otkun TM, Ekuklu G, Kucukugurluoglu Y. Rubella seroprevalance among Turkish adolescent girls living in Edirne, Turkey. Turk J Pediatr. 2006;48:288-93.

11. Sasmaz T, Kurt AO, Ozturk C, Bugdayci R, Oner S. Rubella seroprevalence in women in reproductive period, Mersin, Turkey. Vaccine. 2007;25(5):912-7.

12. Seker S, Abasiyanik MF, Salih BA. Rubella immune status of pregnant and non-pregnant women in Istanbul, Turkey. Saudi Med J. 2004;25(5):575-9.

13. Akbaba M, Sutoluk Z, Yucel B, Ozdener N. Dogankent S.E.A.B.2003 Çalişma Raporu, [Dogankent Primary Health Center Study Report]. [Turkish].2003; Adana

14. LABORSTA Internet. Main statistics (annual) - Employement. International Labour Organization. Accessed May 2009]. Available from: http://laborsta.ilo. org/applv8/data/c2e.html.

15. Oz N. Sivas Bölgesinde Cesitli Yas Gruplarinda Kızamikcik Antikor Durumunun Araştirilmasi. Yüksek lisans tezi, Cumhuriyet Üniversitesi Saglik Bilimleri Enstitusu, [Determination of Rubella Antibody in different age groups in Sivas. Thesis, Cumhuriyet University, Health Sciences Institude].[ Turkish]. 1984; Sivas.

16. Cengiz AT, Kiyan M, Dolapci GI, Aysev D, Tibet M. Cesitli yaslardan çocuklarin serumlarinda rubella IgG ve IgM antikorlarinin ELISA ile araştirilmasi [Serum rubella IgG and IgM antibodies with ELISA in different age groups]. [Turkish]. Infeksiyon Dergisi (Turkish J Infect.). 1996;10:249-52

17. Doroudchi M, Dehaghani AS, Emad K, Ghaderi AA. Seroepidemiological survey of rubella immunity among three populations in Shiraz, Islamic Republic of Iran. East Mediterr Health J. 2001;7(1-2):128-38.

18. Bhaskaram P, Pamalakshmi BA, Raju LA, Raman L. Need for protection against rubella in India. Indian J Pediatr. 1991;58(6):811-4.

19. Omanga U, Goussard B, Kapepela K, Bamba M, Salaun JJ, Piollet M. [Seroprevalence of rubella in Kinshasa (Zaire)]. [French]. Bull Soc Pathol Exot. 1991;84(5 Pt 5): 94-1001.

20. Condorelli F, Stivala A, Gallo R, Marino A, Battaglini CM, Messina A, et al. Use of a microquantity enzyme immunassay in a large-scale study of measles, mumps and rubella immunity in Italy. Eur J Clin Microbiol Infect Dis. 1998;17:49-52

21. Desgrandchamps D, Schaad UB, Glaus J, Tusch G, Heininger U. [Seroprevalence of IgG antibodies against measles, mumps and rubella in Swiss children during the first 16 months of life].[German]. Schweiz Med Wochenschr. 2000;130:1479-86.

22. Nicoara C, Zach K, Traschsel D, Germann D, Matter L. Decay of passively acquired maternal antibodies against measles, mumps and rubella viruses. Clin Diagn Lab Immunol. 1999;6(6):868-71.

23. El-Khateeb MS, Tarawneh MS, Hijazi S, Kahwaji L. Seroimmunity to rubella virus in Jordanians. Public Health. 1983;97(4):204-7.

24. Odelola HA, Familusi JB, Akinyema A. Rubella immunity in Nigerian children. Trans R Soc Trop Hyg. 1980;74(6):743-4.

25. Strauss J, Dobahi SS, Danes L, Kopecky K, Svandova E. Serological survey of rubella in Yemen in 1985. J Hyg Epidemiol Microbiol Immunol. 1989;33(2): 163-7. 
26. Abdullah MA, Jamjoom G, Karar ZA, Badreldine A, Al Jishi N, Taha SA. Seroepidemiology of rubella in Saudi Arabia: an adapted vaccination policy. J. Epidemiol Community Health. 1984;38(3):236-9.

27. Gebreel AO, Gilles HM, Prescott JE. Studies on the seroepidemiology of endemic disease in Libya. II. Rubella. Ann Trop Med Parasitol. 1984;78(5):519-25.

28. Fu-Jen Yuan C, Heung-Tat N. Seroepidemiologic study of rubella in Taiwan's female population. Am J Public Health. 1988;78(10):1366-7.

29. Bartoloni A, Bartalesi F, Roselli M, Mantella A, Dini F, Carballo ES Seroprevalence of varicella zoster and rubella antibodies among rural populations of the Chaco region, South-eastern Bolivia. Trop Med Int Health. 2002;7(6):512-7.

30. Assefa A. Viral diseases in Ethiopia: a review. East Afr Med J. 1993;70(10):624-6

31. Epidemiology of communicable diseases in Europe, 2007. In: Annual Epidemiological Report on Communicable Disease in Europe. Stockholm: European Centre for Disease Prevention and Control. Available from: http://www.ecdc.europa.eu/en/publications/Publications/0706_SUR_Annual Epidemiological_Report_2007.pdf.

32. Pandolfi E, Chiaradia G, Moncada M, Rava L, Tozzi AE. Prevention of congenital rubella and congenital varicella in Europe. Euro Surveill. 2009;14(9):pii=19133. Available from: http://www.eurosurveillance.org/ ViewArticle.aspx?ArticleId $=19133$

33. Kanbur NO, Derman O, Kutluk T, Kinik E. Age specific rubella seroprevalence of an unvaccinated population of adolescents in Ankara, Turkey. Jpn J Infect Dis. 2003;56(1):23-5.

34. Gutíerrez Trujillo G, Muñoz O, Tapia Conyer R, Bustamante Calvillo ME, Alvarez y Muñoz MT, Guiscafré Gallardo JP, et al. [The seroepidemiology of rubella in Mexican women. A national probability survey]. [Spanish]. Salud Publica Mex. 1990;32(6):623-31. 